\title{
LA FORMACIÓN PERMANENTE DE LOS SACERDOTES
}

DOI: https://doi.org/10.52039/seminarios.v59i208.259

Es muy común que los jóvenes sacerdotes y consagrados, al empezar a ejercer el ministerio, se dejen absorber por la actividad pastoral hasta el punto de no sentir necesidad de ningún itinerario formativo que no esté directamente en función de la acción apostólica. Cuando el trabajo pastoral, por muy generoso que sea, se vive de un modo absorbente y equívoco, o cuando la entrega de uno mismo no nace del encuentro con Dios y la caridad pastoral, en lugar de formar deforma, desfigura, agota las fuerzas. En cualquier caso, conviene no olvidar que el trabajo apostólico no es nunca algo neutro: o forma o deforma.

Por otra parte, los sacerdotes mayores no se sienten ya con capacidad para aprender nuevos métodos pastorales y mucho menos con ganas de revisar su vivencia y ejercicio del ministerio sacerdotal y pueden ceder con facilidad a la tentación de no cultivar la formación permanente como algo a lo que está vinculado su bien personal, como discípulos de Cristo y como sacerdotes.

Quedarían, por tanto, los sacerdotes de mediana edad como los más sensibilizados para la formación permanente. Pero muchos de ellos se sienten defraudados por unas actividades formativas que han consistido solamente en una pura actualización teológica, una puesta al día en los temas de carácter moral, sin llegar a transformar realmente su persona y ayudarles a vivir su ministerio como una con-formación con Cristo, buen Pastor.

No obstante todo esto, hemos de reconocer que los mismos sacerdotes «sufren una excesiva dispersión en las actividades pastorales y, frente a la problemática de la sociedad y de la cultura contemporáneas, se sienten impulsados a replantearse su estilo de vida y las prioridades de los trabajos pastorales, a la vez que notan cada vez más la necesidad de una formación permanente» (PDV 3). El capítulo $6^{\circ}$ que el beato Juan Pablo II dedica en la Exhortación postsinodal Pastores dabo vobis a la formación permanente de los sacerdotes es una preciosa pieza de antropología cristiana, de teología del sacerdocio y de pedagogía pastoral aplicada al ministerio sacerdotal. En realidad, la Exhortación abre multitud de perspectivas nuevas que orientan hacia las vías de solución profunda del problema que comentamos. A ella nos referiremos con frecuencia.

* Obispo de Mondoñedo-El Ferrol. 
Hoy día, en que no pocos sacerdotes que sobrepasan los 65 o los 70 años han de atender más parroquias de las que venían atendiendo y experimentan que las fuerzas físicas escasean y el ánimo decae conviene tener muy presente esta propuesta de Juan Pablo II: «También los sacerdotes que, por cansancio o enfermedad, se encuentran en una condición de debilidad física o de cansancio moral, pueden ser ayudados con una formación permanente que los estimule a continuar, de manera serena y decidida, su servicio a la Iglesia; a no aislarse de la comunidad ni del presbiterio; a reducir la actividad externa para dedicarse a aquellos actos de relación pastoral y de espiritualidad personal, capaces de sostener las motivaciones y la alegría de su sacerdocio. La formación permanente les ayudará, en particular, a mantener vivo el convencimiento que ellos mismos han inculcado a los fieles, a saber, la convicción de seguir siendo miembros activos en la edificación de la Iglesia, especialmente en virtud de su unión con Jesucristo doliente y con tantos hermanos y hermanas que en la Iglesia participan en la Pasión del Señor, reviviendo la experiencia espiritual de Pablo que decía: 'Ahora me alegro por los padecimientos que soporto por vosotros, y completo en mi carne lo que falta a las tribulaciones de Cristo' (Col 1, 24)» (PDV 77).

\section{Necesidad de La Formación PeRmanente en los presbíteros}

La Formación Permanente [en adelante, FP] de los sacerdotes es decisiva dado el momento de «rápidas transformaciones sociales» que vive la humanidad, en particular, en la era de la globalización, entendida también como facilidad de comunicación y de información. Rasgos del momento presente como el pluralismo religioso, una cultura penetrada por el relativismo y el secularismo en la que se niega a Dios o se pretende situarle en los márgenes de la vida, un mundo donde las nuevas tecnologías en el orden de la comunicación están creando un nuevo tipo de persona, interpelan continuamente y desafían a los sacerdotes en su vida y quehacer pastoral (cf. PDV 70).

Pero el nuevo planteamiento de la FP de los sacerdotes no descansa en estas y otras razones, sino que todas ellas quedan asumidas y especificadas por las razones teológicas que se pueden profundizar ulteriormente. La FP del presbítero tiene «su propio fundamento y su razón de ser original en el dinamismo del sacramento del orden. Es, en efecto, un 'reavivar', un 'encender' de nuevo la gracia recibida en el presbiterado, de forma que no se pierda la 'novedad permanente propia de todo don de Dios', y que sea posible 'vivirlo en su inmarcesible frescor y belleza originaria'» (PDV 70). Además de una vocación «al» sacerdocio, «se puede hablar de una vocación 'en'el sacerdocio. En realidad, Dios sigue llamando y enviando, revelando su designio salvífico en el desarrollo histórico de la vida del sacerdote y de las vicisitudes de la Iglesia y de la sociedad. Y precisamente en esta perspectiva emerge el significado de la formación permanente; ésta es necesaria para discernir y seguir esta continua llamada o voluntad de 
Dios» (PDV 70). A continuación cita el Papa el caso del apóstol Pedro que escucha al comienzo de su discipulado y al final de su vida el «Sígueme» (Jn 21, 17-19), que la marca por entero.

Benedicto XVI hace una aplicación a la situación actual: «En una época como la nuestra, tan 'policéntrica' e inclinada a atenuar todo tipo de concepción que afirme una identidad, que muchos consideran contraria a la libertad y a la democracia, importa tener muy clara la peculiaridad teológica del ministerio ordenado para no caer en la tentación de reducirlo a las categorías culturales dominantes. En un contexto de secularización generalizada, que excluye progresivamente a Dios del ámbito público y tiende a excluirlo también de la conciencia social compartida, a menudo el sacerdote parece 'extraño' al sentir común, justamente por los aspectos esenciales de su ministerio, como los de ser un hombre de lo sagrado, tomado del mundo para interceder a favor del mundo y constituido en esa misión por Dios y no por los hombres (cf. $\mathrm{Hb} \mathrm{5,1).} \mathrm{Por} \mathrm{ello} \mathrm{es} \mathrm{importante} \mathrm{superar} \mathrm{peligrosos} \mathrm{re-}$ duccionismos que, en los decenios pasados, utilizando categorías más funcionales que ontológicas, han presentado al sacerdote casi como a un 'agente social', con el riesgo de traicionar incluso el sacerdocio de Cristo. La hermenéutica de la continuidad se revela cada vez más urgente para comprender de modo adecuado los textos del concilio ecuménico Vaticano II y, análogamente, resulta necesaria una hermenéutica que podríamos definir 'de la continuidad sacerdotal', la cual, partiendo de Jesús de Nazaret, Señor y Cristo, y pasando por los dos mil años de la historia de grandeza y de santidad, de cultura y de piedad, que el sacerdocio ha escrito en el mundo, ha de llegar hasta nuestros días» ${ }^{1}$.

Esta perspectiva permite abordar la FP, no como un deber o una necesidad extrínsecos a la vida del sacerdote, y menos aún como una especie de pausa en su ministerio. «Es más bien una exigencia intrínseca del don recibido», recordaba Juan Pablo II en PDV 70. Esta exigencia brota del centro mismo de la persona del sacerdote, que ha sido tocado por la gracia del sacramento para configurarlo con Jesucristo y así poder personificarle en la Iglesia. Podemos, pues, hacer nuestra la impactante afirmación de A. Cencini: «Si nuestra vida de presbíteros o consagrados no es formación permanente, será frustración permanente»².

\section{LA FORMACIÓN CONTINUA DEL SACERDOTE CONSTITUYE UNA LLAMADA A SU CON- TINUA CONVERSIÓN Y SANTIFICACIÓN.}

La formación permanente «es un proceso de continua conversión, es amor a Dios y a todos los hombres que tienen el derecho de ver y de encontrar en el sacerdote al mismo Cristo». Por eso la formación permanente del sacerdote está estrechamente vinculada a su relación con Cristo y con la Iglesia.

1. Benedicto XVI, Discurso en el Congreso de la Congregación para el Clero.

2. A. Cencini, La formación permanente, Madrid 2002, 23. 
A la relación con Cristo, porque el «sí» del sacerdote a la llamada de Dios «deberá renovarse y reafirmarse continuamente durante los años del sacerdocio en otras numerosísimas respuestas, enraizadas todas ellas y vivificadas por el 'si' del Orden sagrado» (PDV 70). La FP del sacerdote es el diario redescubrimiento de la absoluta necesidad de la santidad personal, que se concreta en la búsqueda de "ser» y de "vivir» como otro Cristo en todas las circunstancias de su vida, no sólo de aumentar o actualizar su «saber». La FP, por tanto, debe abarcar los diferentes ámbitos de la existencia del sacerdote, y por eso hablamos de sus dimensiones humana y espiritual, intelectual y pastoral. En consecuencia, la formación permanente no puede reducirse a unos cursos de actualización teológica o pastoral, aunque éstos sean necesarios. La FP ha de dirigirse al centro de la persona, allí donde se ponen en juego las orientaciones fundamentales de la mente y del corazón en relación con el significado de la propia vida, y las decisiones básicas de la libertad. $Y$ ha de conducir al sacerdote a un crecimiento personal como sacerdote.

La FP del sacerdote está también vinculada a su relación con la Iglesia, porque la formación del sacerdote es «un acto de amor al Pueblo de Dios», un "acto de justicia verdadera y propia», dado que el sacerdote «es deudor para con el Pueblo de Dios», a quien Cristo ha donado la persona del sacerdote, y a quien pertenece, con verdadero derecho, su ministerio pastoral (PDV 70). En el fondo, la formación permanente del sacerdote es una 'exigencia' de fidelidad a su propio ser (PDV 70).

Insistimos en que la FP no puede consistir en una serie de acontecimientos puntuales, al margen de la vida de cada día del sacerdote. La formación del sacerdote ha de ser realmente permanente y no sólo intermitente. Y no puede reducirse a una puesta al día traducida en un esfuerzo -o un fastidio- más.

\section{El deRECHO-DEBER de LA Formación PeRmanente}

La FP es un derecho y un deber de todo sacerdote. Nadie puede suplantar su compromiso responsable, como nadie puede recorrer por él el itinerario del crecimiento y la renovación. Así pues, la FP «es esencial para la vida y el crecimiento del Pueblo de Dios: es un derecho y un deber de todo sacerdote, e impartirla es un derecho-deber de la Iglesia universal, sancionado por la ley canónica», en el canon 279 del Código de Derecho Canónico. La FP del clero hemos de plantearla hoy más como un derecho de los sacerdotes que como un deber.

Un derecho del sacerdote para crecer en su propia identidad como presbíteros: En la Iglesia «misterio» el sacerdote está llamado, mediante la formación permanente, a conservar y desarrollar en la fe la conciencia de la verdad entera y sorprendente de su propio ser, pues él es «ministro de Cristo y administrador de los misterios de Dios» (cf. 1 Cor 4, 1). Pablo pide expresamente a los cristianos que lo consideren según esta identidad; pero él mismo es el primero en ser 
consciente del don sublime recibido del Señor. Así debe ser para todo sacerdote si quiere permanecer en la verdad de su ser. Pero esto es posible sólo en la fe, sólo con la mirada y los ojos de Cristo.

En este sentido, se puede decir que la FP tiende «a hacer que el sacerdote sea una persona profundamente creyente y lo sea cada vez más; que pueda verse con los ojos de Cristo en su verdad completa. Debe custodiar esta verdad con amor agradecido y gozoso; debe renovar su fe cuando ejerce el ministerio sacerdotal: sentirse ministro de Jesucristo, sacramento del amor de Dios al hombre, cada vez que es mediador e instrumento vivo de la gracia de Dios a los hombres; debe reconocer esta misma verdad en sus hermanos sacerdotes. Este es el principio de la estima y el amor hacia ellos» (PDV 73).

Un derecho del sacerdote para responder a las necesidades de la porción del Pueblo de Dios que le ha sido confiado: «Pero es también un acto de amor al Pueblo de Dios, a cuyo servicio está puesto el sacerdote. Más aún, es un acto de justicia verdadera y propia: él es deudor para con el Pueblo de Dios, pues ha sido llamado a reconocer y promover el «derecho» fundamental de ser destinatario de la Palabra de Dios, de los Sacramentos y del servicio de la caridad, que son el contenido original e irrenunciable del ministerio pastoral del sacerdote. La formación permanente es necesaria para que el sacerdote pueda responder debidamente a este derecho del Pueblo de Dios» (PDV 70).

Conviene no olvidar también que es un derecho de los fieles que son al fin y al cabo los que salen perjudicados o beneficiados de una buena o mala FP de los presbíteros. Estos han de vivirla como una expresión privilegiada de su caridad pastoral hacia ellos. «La formación permanente es un derecho que la comunidad siente tener respecto de su sacerdote: para evitar el cansancio, la chapucería y la rutina de la mediocridad, que asignan al sacerdote, a veces inadvertidamente, un papel gregario más que de pastor que camina delante del rebaño» ${ }^{3}$.

\section{Dimensiones de LA Formación PeRmanente}

El Directorio para el ministerio y la vida de los presbíteros insiste en que la FP ha de ser completa, en el sentido que ha de abarcar todas las dimensiones de la persona del sacerdote: «Tal formación debe comprender y armonizar todas las dimensiones de la vida sacerdotal; es decir, debe tender a ayudar a cada presbítero: a desarrollar una personalidad humana madurada en el espíritu de servicio a los demás, cualquiera que sea el encargo recibido; a estar intelectualmente preparado en las ciencias teológicas y también en las humanas en cuanto relacionadas con el propio ministerio, de manera que desempeñe con mayor eficacia su función de testigo de la fe; a poseer una vida espiritual profunda, nutrida por la intimidad con Jesucristo y del amor por la Iglesia; a ejercer su ministerio

3. A. Cencini, La formación permanente, Madrid 2002, 54. 
pastoral con empeño y dedicación. En definitiva, tal formación debe ser completa: humana, espiritual, intelectual, pastoral, sistemática y personalizada» ${ }^{4}$.

Juan Pablo II explicaba el contenido de las diversas dimensiones de la FP del sacerdote en PDV 72.

\section{La dimensión humana}

«Una primera profundización se refiere a la dimensión humana de la formación sacerdotal. En el trato con los hombres y en la vida de cada día, el sacerdote debe acrecentar y profundizar aquella sensibilidad humana que le permite comprender las necesidades y acoger los ruegos, intuir las preguntas no expresadas, compartir las esperanzas y expectativas, las alegrías y los trabajos de la vida ordinaria; ser capaz de encontrar a todos y dialogar con todos. Sobre todo conociendo y compartiendo, es decir, haciendo propia, la experiencia humana del dolor en sus múltiples manifestaciones, desde la indigencia a la enfermedad, desde la marginación a la ignorancia, a la soledad, a las pobrezas materiales y morales, el sacerdote enriquece su propia humanidad y la hace más auténtica y transparente, en un creciente y apasionado amor al hombre».

Al hacer madurar su propia formación humana, el sacerdote recibe una ayuda particular de la gracia de Jesucristo; en efecto, la caridad del buen Pastor se manifestó no sólo con el don de la salvación a los hombres, sino también con la participación de su vida, de la que el Verbo, que se ha hecho «carne» (cf. Jn 1, 14), ha querido conocer la alegría y el sufrimiento, experimentar la fatiga, compartir las emociones, consolar las penas. Viviendo como hombre entre los hombres y con los hombres, Jesucristo ofrece la más absoluta, genuina y perfecta expresión de humanidad; lo vemos festejar las bodas de Caná, visitar a una familia amiga, conmoverse ante la multitud hambrienta que lo sigue, devolver a sus padres hijos que estaban enfermos o muertos, llorar la pérdida de Lázaro.

Del sacerdote, cada vez más maduro en su sensibilidad humana, ha de poder decir el Pueblo de Dios algo parecido a lo que de Jesús dice la Escritura: «No tenemos un Sumo Sacerdote que no pueda compadecerse de nuestras flaquezas, sino probado en todo igual que nosotros, excepto en el pecado» (Heb 4, 15).

\section{La dimensión espiritual}

La formación del presbítero en su dimensión espiritual es una exigencia de la vida nueva y evangélica a la que ha sido llamado de manera específica por el Espíritu Santo infundido en el sacramento del orden. El Espíritu, consagrando al sacerdote y configurándolo con Jesucristo, Cabeza y Pastor, crea una relación que, en el ser mismo del sacerdote, requiere ser asimilada y vivida de manera personal, esto es, consciente y libre, mediante una comunión de vida y amor cada

4. Congregación para el Clero, Directorio para el ministerio y la vida de los presbíteros, 74. 
vez más rica, y una participación cada vez más amplia y radical de los sentimientos y actitudes de Jesucristo. En esta relación entre el Señor Jesús y el sacerdote -relación ontológica y psicológica, sacramental y moral- está el fundamento y a la vez la fuerza para aquella «vida según el Espíritu» y para aquel «radicalismo evangélico» al que está llamado todo sacerdote y que se ve favorecido por la formación permanente en su aspecto espiritual. Esta formación es necesaria también para el ministerio sacerdotal, su autenticidad y fecundidad espiritual. «¿Ejerces la cura de almas?», preguntaba san Carlos Borromeo. Y respondía así en el discurso dirigido a los sacerdotes: «No olvides por eso el cuidado de ti mismo, y no te entregues a los demás hasta el punto de que no quede nada tuyo para ti mismo. Debes tener ciertamente presente a las almas, de las que eres pastor, pero sin olvidarte de ti mismo. Comprended, hermanos, que nada es tan necesario a los eclesiásticos como la meditación que precede, acompaña y sigue todas nuestras acciones: Cantaré, dice el profeta, y meditaré (cf. Sal 100,1). Si administras los sacramentos, hermano, medita lo que haces. Si celebras la Misa, medita lo que ofreces. Si recitas los salmos en el coro, medita a quién y de qué cosa hablas. Si guías a las almas, medita con qué sangre han sido lavadas; y todo se haga entre vosotros en la caridad (1 Cor 16, 14). Así podremos superar las dificultades que encontramos cada día, que son innumerables. Por lo demás, esto lo exige la misión que se os ha confiado. Si así lo hacemos, tendremos la fuerza para engendrar a Cristo en nosotros y en los demás».

En concreto, la vida de oración debe ser «renovada» constantemente en el sacerdote. En efecto, la experiencia enseña que en la oración no se vive de rentas; cada día es preciso no sólo reconquistar la fidelidad exterior a los momentos de oración, sobre todo los destinados a la celebración de la Liturgia de las Horas y los dejados a la libertad personal y no sometidos a tiempos fijos o a horarios del servicio litúrgico, sino que también se necesita, y de modo especial, reanimar la búsqueda continuada de un verdadero encuentro personal con Jesús, de un coloquio confiado con el Padre, de una profunda experiencia del Espíritu 5 .

Lo que el apóstol Pablo dice de los creyentes, que deben llegar «al estado de hombre perfecto, a la madurez de la plenitud de Cristo» (Ef 4,13$)$, se puede aplicar de manera especial a los sacerdotes, llamados a la perfección de la caridad y por tanto a la santidad, porque su mismo ministerio pastoral exige que sean modelos vivientes para todos los fieles.

5. El Directorio concreta así: «Es deseable que cada presbítero, quizás con ocasión de los periódicos ejercicios espirituales, elabore un proyecto concreto de vida personal -a ser posible de acuerdo con el propio director espiritual- para el cual se señalan algunos puntos: 1) meditación diaria sobre la Palabra o sobre un misterio de la fe; 2) encuentro diario y personal con Jesús en la Eucaristía, además de la devota celebración de la Santa Misa; 3) devoción mariana (rosario, consagración o acto de abandono, coloquio íntimo); 4) momento de formación doctrinal y hagiográfica; 5) descanso debido; 6 ) renovado empeño sobre la puesta en práctica de las indicaciones del propio Obispo y de la propia convicción en el modo de adherirse al Magisterio y a la disciplina eclesiástica; 7) cuidado de la comunión y de la amistad sacerdotal». 


\section{La dimensión intelectual}

También esta dimensión formativa requiere que sea continuada y profundizada durante toda la vida del sacerdote, concretamente mediante el estudio y la actualización cultural seria y comprometida. El sacerdote, participando de la misión profética de Jesús e inserto en el misterio de la Iglesia, Maestra de verdad, está llamado a revelar a los hombres el rostro de Dios en Jesucristo y, por ello, el verdadero rostro del hombre. Pero esto exige que el mismo sacerdote busque este rostro y lo contemple con veneración y amor (cf. Sal 26, 8; 41, 2); sólo así puede darlo a conocer a los demás. En particular, la perseverancia en el estudio teológico resulta también necesaria para que el sacerdote pueda cumplir con fidelidad el ministerio de la Palabra, anunciándola sin titubeos ni ambigüedades, distinguiéndola de las simples opiniones humanas, aunque sean famosas y difundidas. Así, podrá ponerse de verdad al servicio del Pueblo de Dios, ayudándolo a dar razón de la esperanza cristiana a cuantos se la pidan (cf. 1 Pe 3, 15). Además, «el sacerdote, al aplicarse con conciencia y constancia al estudio teológico, es capaz de asimilar, de forma segura y personal, la genuina riqueza eclesial. Puede, por tanto, cumplir la misión que lo compromete a responder a las dificultades de la auténtica doctrina católica y superar la inclinación, propia y de otros, al disenso y a la actitud negativa hacia el magisterio y hacia la tradición».

\section{La dimensión pastoral}

El aspecto pastoral de la formación permanente queda bien expresado en las palabras del apóstol Pedro: «Que cada cual ponga al servicio de los demás la gracia que ha recibido, como buenos administradores de las diversas gracias de Dios» (1 Pe 4, 10). Para vivir cada día según la gracia recibida, es necesario que el sacerdote esté cada vez más abierto a acoger la caridad pastoral de Jesucristo, que le confirió su Espíritu Santo con el sacramento recibido6. Así como toda la actividad del Señor ha sido fruto y signo de la caridad pastoral, de la misma manera debe ser también para la actividad ministerial del sacerdote. La caridad pastoral es un don y un deber, una gracia y una responsabilidad, a la que es preciso ser fieles, es decir, hay que asumirla y vivir su dinamismo hasta las exigencias más radicales. Esta misma caridad pastoral, como se ha dicho, empuja y estimula al sacerdote a conocer cada vez mejor la situación real de los hombres a quienes ha sido enviado; a discernir la voz del Espíritu en las circunstancias históricas en las que se encuentra; a buscar los métodos más adecuados

6. Recordemos la advertencia del cardenal Amigo: «La pastoral no es simplemente un conjunto de experiencias y métodos. Tiene categoría teológica, porque recibe de la fe los principios y criterios de la acción pastoral de la Iglesia. Con la formación pastoral no se trata de asegurar una competencia técnica, sino de garantizar las disposiciones que no son otras que aquella que la Iglesia ve reflejadas en el Buen Pastor (PDV 57)» (C. Amigo, El sacerdote del Tercer Milenio: Ecclesia 2963 (1999) 7). 
y las formas más útiles para ejercer hoy su ministerio. De este modo, la caridad pastoral animará y sostendrá los esfuerzos humanos del sacerdote para que su actividad pastoral sea actual, creíble y eficaz. Mas esto exige una formación pastoral permanente.

El camino hacia la madurez no requiere sólo que el sacerdote continúe profundizando los diversos aspectos de su formación sino que exige también, y sobre todo, que sepa integrar cada vez más armónicamente estos mismos aspectos entre sí, alcanzando progresivamente la unidad interior, que la caridad pastoral garantiza. De hecho, ésta no sólo coordina y unifica los diversos aspectos, sino que los concreta como propios de la formación del sacerdote, en cuanto transparencia, imagen viva y ministro de Jesús, buen Pastor.

La formación permanente ayuda al sacerdote a superar la tentación de llevar su ministerio a un activismo finalizado en sí mismo, a una prestación impersonal de servicios, sean espirituales o sagrados, a una especie de empleo en la organización eclesiástica. Sólo la formación permanente ayuda al «sacerdote» a custodiar con amor vigilante el «misterio» del que es portador para el bien de la Iglesia y de la humanidad.

Finalmente, el Directorio, en los números 79 y 80 , habla de que la FP de los sacerdotes ha de ser sistemática y personalizada.

\section{FORMACIÓN INICIAL Y FORMACIÓN PERMANENTE}

La FP no es sólo la que sigue a la inicial, sino que la precede y la hace posible. Es como el seno que la cobija y le da identidad. No es simplemente una puesta al día, de diverso tipo, ni una momentánea parada justamente para no agotarse y poder comenzar después el trabajo con mayor energía. No es actividad extraordinaria o tiempo sabático en momentos excepcionales, sino un modo de vivir de modo pleno e intenso la vida ordinaria, dejándose tocar por Dios que nos habla a través de la historia, de los hermanos, dejándose formar por los acontecimientos ordinarios y por los imprevistos. FP es estar despierto para acoger la llamada de Dios que se renueva cada día.

La FP debe ir muy en conexión con la «formación inicial» que se imparte en el Seminario. Ambas deben formar un único proyecto orgánico de vida cristiana y sacerdotal, cuyo centro es el sacramento del orden. Más aún, la primacía no la tendría la formación inicial, de la cual la permanente no sería sino un retoque, una actualización y puesta al día. Por paradójico que pueda parecer, la FP es, como hemos dicho, algo que precede a la formación inicial y la hace posible. Es la entraña generadora que la custodia y le da identidad.

Es de mucha importancia darse cuenta y respetar la intrínseca relación que hay entre la formación que precede a la Ordenación y la que le sigue. En efecto, si hubiese una discontinuidad o incluso una deformación entre estas dos fases formativas, se seguirían inmediatamente consecuencias graves para la actividad pastoral y para la comunión fraterna entre 
los presbíteros, particularmente entre los de diferente edad. La formación permanente no es una repetición de la recibida en el Seminario y que ahora es sometida a revisión o ampliada con nuevas sugerencias prácticas, sino que se desarrolla con contenidos y sobre todo a través de métodos relativamente nuevos, como un hecho vital unitario que, en su progreso -teniendo sus raíces en la formación del seminario- requiere adaptaciones, actualizaciones y modificaciones, pero sin rupturas ni solución de continuidad.

Y viceversa, desde el Seminario mayor es preciso preparar la futura formación permanente y fomentar el ánimo y el deseo de los futuros presbíteros en relación con ella, demostrando su necesidad, ventajas y espíritu, y asegurando las condiciones de su realización.

Precisamente porque la formación permanente es una continuación de la del Seminario, su finalidad no puede ser una mera actitud, que podría decirse, «profesional», conseguida mediante el aprendizaje de algunas técnicas pastorales nuevas. Debe ser más bien el mantener vivo un proceso general e integral de continua maduración, mediante la profundización, tanto de los diversos aspectos de la formación -humana, espiritual, intelectual y pastoral-como de su específica orientación vital e íntima, a partir de la caridad pastoral y en relación con ella (PDV 71).

En definitiva, sólo una adecuada FP logra mantener al sacerdote en lo que es esencial y decisivo para su ministerio: la fidelidad: «Ahora bien, lo que en fin de cuentas se exige de los administradores es que sean fieles» (1 Cor 4, 2). «Permitidme que os abra mi corazón -decía Benedicto XVI en Fátima- para deciros que la principal preocupación de cada cristiano, especialmente de la persona consagrada y del ministro del altar, debe ser la fidelidad, la lealtad a la propia vocación, como discípulo que quiere seguir al Señor. La fidelidad a lo largo del tiempo es el nombre del amor; de un amor coherente, verdadero y profundo a Cristo Sacerdote» ${ }^{7}$.

Por tanto, en cada diócesis ha de transmitirse un mensaje inequívoco y fuerte: todos (obispo, sacerdotes, consagrados y fieles laicos) hemos de situarnos en una lógica de formación permanente y hemos de sentirla como algo vinculante, no como algo dejado a la discreción del individuo.

7. Benedicto XVI, Discurso en la celebración de las Vísperas, Fátima, 12.05.2010. 